CORRIGENDUM OPEN

\title{
Fatigue in Parkinson's disease: report from a multidisciplinary symposium
}

Joseph H Friedman, James C Beck, Kelvin L Chou, Gracia Clark, Christopher P Fagundes, Christopher G Goetz, Karen Herlofson, Benzi Kluger, Lauren B Krupp, Anthony E Lang, Jao-Shin Lou, Laura Marsh, Anne Newbould and Daniel Weintraub

npj Parkinson's Disease (2017) 3, 17001; doi:10.1038/npjparkd.2017.1; published online 20 October 2017

Correction to: npj Parkinson's Disease (2016) 2, 15025. doi: 10.1038/npjparkd.2015.25; published online 14 January 2016

The original version of this Article contained an error in the spelling of the title, in which 'multidisciplinary' was incorrectly given as 'mutidisciplinary'. This has now been corrected in both the PDF and HTML versions of the Article.

A correction has been published and is appended to both the HTML and PDF versions of this paper. The error has been fixed in the paper.

\begin{abstract}
(i) This work is licensed under a Creative Commons Attribution 4.0 International License. The images or other third party material in this article are included in the article's Creative Commons license, unless indicated otherwise in the credit line; if the material is not included under the Creative Commons license, users will need to obtain permission from the license holder to reproduce the material. To view a copy of this license, visit http://creativecommons.org/licenses/ by/4.0/
\end{abstract}

(c) The Author(s) 2017 